\title{
A tomada de notas em interpretação consecutiva: algumas considerações históricas
}

\section{Note-taking in consecutive interpreting: a brief historical perspective}

\author{
Tito Lívio Cruz Romão*
}

Que los descubridores lleven intérpretes, y se informen de lo que esta ley declara.

Don Carlos II

Resumo: Neste artigo, primeiramente será apresentado um breve panorama histórico da atividade exercida por intérpretes consecutivos ao longo dos séculos. Em seguida, serão abordadas e discutidas algumas informações relevantes sobre os trabalhos de J ean Herbert, J ean-François Rozan Heinz Matyssek, Danica Seleskovitch e Marianne Lederer. Estes estudiosos dedicaram parte de suas pesquisas à elaboração de técnicas de tomada de notas para interpretação consecutiva. Por fim, serão feitas considerações sobre o papel de destaque que cabe à técnica de anotações para interpretação consecutiva proposta por Heinz Matyssek.

Palavras-chave: interpretação consecutiva; tomada de notas.

Abstract: The first part of this article presents a brief historical perspective on the activity of consecutive interpreting over the centuries. In its second part, some relevant information on the works done by J ean Herbert, J ean-François Rozan, Heinz Matyssek, Danica Seleskovitch and Marianne Lederer will be presented and discussed. These scholars concentrated part of their researches on the elaboration of note-taking methods for consecutive interpreting. Finally, this article will focus on the leading role

\footnotetext{
* Pós-Graduação em Estudos da Tradução (POET) / Departamento de Letras Estrangeiras (DLE)
} da Universidade Federal do Ceará. E-mail: cruzromao@terra.com.br 
RomÃo, T. L. C - A tomada de notas em interpretação consecutiva: algumas considerações históricas

played by the note-taking method for consecutive interpreting that was proposed by Heinz Matyssek.

Keywords: consecutive interpreting; note-taking.

\section{Alguns aspectos históricos da interpretação ${ }^{1}$}

Em seu livro História, uma narrativa escrita por volta de 440 a.C. e dividida em nove capítulos, cada um deles dedicado a uma das musas gregas, 0 historiador Heródoto² faz cerca de dez menções à figura do intérprete, destacando, como ilustração, a importância desse profissional no Egito antigo, em meio a outras classes de trabalhadores:

Os egípcios estão divididos em sete classes distintas, cuj os nomes são: sacerdotes, guerreiros, vaqueiros, porqueiros, negociantes, intérpretes e barqueiros. São essas as classes dos egípcios, e seus nomes provêm de suas atividades específicas. (HeRôDOTOS 1985: 142)

Ressalve-se que o destaque dado por Heródoto à classe de intérpretes também encontra comprovação histórica mediante uma imagem esculpida no túmulo do faraó Horemheb (c. 1350 a.C.), que foi o sucessor de Tutancâmon em Mênfis. De forma simbólica, o escultor soube exprimir, em sua obra, a

\footnotetext{
${ }^{1}$ As considerações apresentadas a seguir restringem-se, quanto à menção a intérpretes feita por Heródoto e por Vicente Guillermo Arnaud, basicamente à interpretação de acompanhamento ou "de enlace" (v. HURTADO-ALBIR 2013: 82) e, no tocante ao século XX, à interpretação consecutiva. Observe-se ainda que a escolha dos períodos aqui analisados representam recortes de épocas bastante distintas da História em geral e da história da prática da interpretação em particular, como tentativa de ressaltar, de acordo com a época, a predominância da interpretação de enlace ou da interpretação consecutiva e, consequentemente, do maior ou menor recurso a uma técnica de anotações.

${ }^{2}$ As citações extraídas da obra de Heródoto serão apresentadas neste artigo a partir da tradução brasileira de Mário da Gama Kury, que, ao verter o nome do historiador grego em questão, apenas transliterou seu nome, utilizando, assim, a grafia Herôdotos, que imita a pronúncia grega.
} 
RomÃo, T. L. C - A tomada de notas em interpretação consecutiva: algumas considerações históricas

função mediadora do intérprete, apresentando uma imagem dupla deste profissional. "Do lado esquerdo, o intérprete ouve emissários sírios e líbios; (...) do lado direito, o intérprete transmite a mensagem para Horemheb, que poderá então dirigir-se diretamente ao faraó" (DELISLE \& WOODSWORTH 1998: 297s.). À época, Horemheb era vice-rei e também comandante do exército, funcionando também, na cena aqui descrita, como mediador entre o intérprete e o faraó.

Em um outro trecho de sua História, Heródoto (1985: 207) evidencia a profusão de línguas em que negociavam os citas, um povo antigo que dominou as estepes do Pontos e do Mar Cáspio, como se pode deduzir a partir destas suas palavras:

Então até esses [montes] calvos conhecemos claramente o território e também os seus habitantes; de fato, alguns citas vão até lá e não é difícil interrogá-los, inclusive para os helenos do porto de Borístenes e de outros portos do Pontos; os visitantes citas usam para seus negócios com os agripaios sete intérpretes e sete línguas. (HERôDOTOS 1985: 207)

Ainda em outro excerto de seus profusos depoimentos sobre os fatos ocorridos na Antiguidade, o célebre historiador grego, ao visitar a pirâmide construída por Quéops, destaca uma vez mais a presença de um intérprete:

0 topo da pirâmide primeiro, em seguida as plataformas abaixo, e finalmente a base e a parte inferior. Há uma inscrição em caracteres egípcios na pirâmide registrando quanto foi dispendido em rábanos silvestres, cebolas e alhos para os trabalhadores, e até onde posso lembrar com precisão o intérprete, quando leu para mim as palavras da inscrição, disse que a quantia paga se elevou a mil e seiscentos talentos de prata. (HERÔDOTOS 1985: 120)

É importante lembrar que, em todas as situações acima descritas, estáse diante da figura de um intérprete de enlace, se nos apoiarmos na definição de HURTADO-ALBIR (2013: 82) sobre a modalidade de interpretação chamada 
RomÃo, T. L. C - A tomada de notas em interpretação consecutiva: algumas considerações históricas

"interpretação de enlace ou consecutiva dialógica". Segundo a autora, ali se enquadram os seguintes gêneros textuais orais: entrevista (jornalística, de trabalho etc.), debate, negociação, treinamento (esportivo, artístico, militar etc.), curso de formação, exame oral, audiência em tribunal, interrogatório, cerimônias etc. Pelas condições técnicas impostas pelas formas e materiais de escrita da época, apenas se poderia supor, sem maior certeza, que o intérprete de enlace nas épocas históricas descritas nos parágrafos anteriores não recorria a um método de tomada de notas, apoiando-se tão-somente em sua memória.

Muitos séculos mais tarde, ver-se-iam, em plena América hispânica, situações em que também se recorreria ao trabalho de intérpretes. Em um livro rico em pormenores sobre aspectos históricos e legais da profissão de tradutor (e intérprete) público, o autor argentino Vicente Guillermo Arnaud, dando-nos pistas sobre o que ocorria à época dos grandes descobrimentos, faz a seguinte observação inicial:

En América la historia de los intérpretes se inicia desde el mismo momento en que Cristóbal Colón entra en comunicación con los naturales de las tierras que descubrió el 12 de octubre de 1492. Sus intérpretes de árabe y hebreo en nada le servieron para entender a los indios y cuando continua su viaje, el 14 de octubre, adopta como primera medida el embarcar a seis indios para utilizarlos como guías y futuros intérpretes. El cautivo de mayor actuación fue bautizado con el nombre de Diego Colón, realizó el segundo viaje con el Almirante y sus servicios le fueron indispensables. Siempre fue constante su preocupación por proveerse de intérpretes y en ese sentido aconsejó a la Corona de España y a los expedicionarios que le siguieron. (ARNAUD 1958: 15)

Através desse testemunho que Arnaud colheu em suas extensas pesquisas, é lícito observar que as grandes expedições realizadas pelos europeus a partir do século XV, em busca das Índias ou simplesmente de novas terras, normalmente vinham acompanhadas do cuidado em que se estabelecessem contatos com os povos desconhecidos e, para tanto, da necessidade de intérpretes. Como o próprio Arnaud ressalta acima, apesar da 
RomÃo, T. L. C - A tomada de notas em interpretação consecutiva: algumas considerações históricas

preocupação preventiva de Colombo, seus intérpretes não Ihe foram úteis, uma vez que o navegador, ao aportar nas novas terras, deparou-se com línguas totalmente incógnitas e diferentes daquelas já conhecidas pelos europeus. Ao longo do processo de colonização no subcontinente americano, os espanhóis rapidamente encontraram meios de "formar" seus intérpretes, graças, a título de exemplo, às missões religiosas por eles implantadas:

En un período posterior, pero siempre en la época de la conquista, al estudiar la labor civilizadora y cultural que realizaron los religiosos entre los indios, comprobamos la dura oposición que fue siempre la diversidad y multiplicidad de las lenguas de los naturales, que entorpecía la catequización de los indios y obligaba a los misioneros a recurrir a intérpretes y a aprender las lenguas indígenas, creándose cátedras para su enseñanza, confeccionándose vocabularios, diccionarios, gramáticas, etc. (ARNAUD 1958: 16)

Depreende-se do trecho acima que os missionários estabelecidos na Hispano-América, assim como ocorreu em terras ameríndias colonizadas pelos portugueses ${ }^{3}$, empenharam-se em adquirir o domínio de diferentes idiomas nativos do chamado Novo Mundo e em criar instrumentos (p.ex. gramáticas e dicionários) que viabilizassem a expansão dos novos conhecimentos. Não se encontram registros, todavia, de que os intérpretes recorressem a algum tipo de técnica de anotações que Ihes servisse de apoio em suas lides profissionais cotidianas.

\footnotetext{
${ }^{3}$ Sobre a vinda de "intérpretes" na expedição de Pedro Álvares Cabral, BuENo (1998: 98) afirma: “Então, na areia, às margens daquele regato, entre a mata e o mar, os portugueses viram 'homens que andavam pela praia, obra de sete ou oito'. A um sinal do comandante-mor, os capitães dos outros navios embarcaram em batéis e esquifes (barcos pequenos, tipo escaler) e se dirigiram à nau capitânia para uma breve reunião. Logo após ela, Cabral decidiu enviar à terra o experiente Nicolau Coelho, que estivera na Índia com Vasco da Gama, 'o judeu da Índia' - que, além do árabe, falava os dialetos hindus da Costa do Malabar -, mais um grumete da Guiné e um escravo de Angola. Os portugueses conseguiam reunir, assim, a bordo de um escaler, homens dos três continentes conhecidos até então e capazes de falar seis ou sete línguas diferentes."
} 
RomÃo, T. L. C - A tomada de notas em interpretação consecutiva: algumas considerações históricas

Vale ressaltar, aqui, que a Coroa Espanhola dispunha de grande sofisticação administrativa. Contava, por exemplo, com um sistema judiciário bem elaborado, que também era aplicável em suas colônias de além-mar. Porém, as leis, embora previssem a utilização de intérpretes para índios, não 0 faziam em relação a negros, como informa Arnaud:

En el derecho indiano ninguna ley establecía la existencia de intérpretes para los negros, como lo establecía en cambio para los Indios. Pero el arbitrio judicial suplía el vacío legal cuando el reo era bozal o bozalón y su confesión se consideraba necesaria, por medio de intérpretes y aun acudiendo a otras diligencias. (ARNAUD 1958: 20)

Em seus pormenores sobre a atuação de intérpretes, Arnaud sublinha a atuação destes no âmbito da Real Audiência de Buenos Aires, criada com base na Real Cédula de 6 de abril de 1661, de Felipe IV, e inserida no grande ViceReino do Peru, que se estendia em quase toda a atual América do Sul, à exceção do leste brasileiro, alcançando inclusive o istmo panamenho. Dentre as muitas informações - de grande valor histórico e com comprovação documental colhidas por Arnaud, encontram-se relatos, à guisa de ilustração, sobre as normas relativas à atuação profissional de intérpretes naquela imensa área geográfica, assim como sobre certas qualidades de que estes deveriam ser portadores. Vejam-se, a seguir, alguns exemplos:

Los intérpretes estaban comprendidos entre los oficiales menores de las Audiencias. Entre las cualidades morales que se les exigía figuraban las de ser fieles, cristianos y bondadosos, por ser ellos el instrumento por intermedio del cual se hacía justicia, se gobernaba a los indios y se enmendaban los agravios que recibían, ayudándolos y favoreciéndolos. Los presidentes y oidores de las Audiencias debían poner gran cuidado en observar la moralidad del intérprete y cualquier delito que se presumiere y averiguara contra su fidelidad debía ser castigado con todo rigor. (...) Los intérpretes 0 "intérpretas" no podían aceptar presentes, dádivas ni promesas de los españoles o indios ni de otras personas que tuvieren o esperasen 
RomÃo, T. L. C - A tomada de notas em interpretação consecutiva: algumas considerações históricas

tener con ellos pleitos o negocios, cualquiera fuera la importancia de éstos. No podían aceptar obsequios de ninguna especie, valor 0 cantidad, ni siquiera comidas o bebidas, aunque fueran of recidos, dados o prometidos sin ellos pedirlos ni que otros los pidieran por ellos. (ARNAUD 1958: 24)

Na passagem acima, em que o autor descreve uma espécie de código deontológico estabelecido pelas autoridades da Coroa Espanhola para intérpretes, merece especial destaque que Arnaud tenha encontrado referências ao exercício da interpretação por mulheres já àquela época. Em seu estudo, o pesquisador argentino mostra, além dos aspectos recém-relatados, vários outros que atualmente talvez figurassem em um código de ética de uma associação profissional de intérpretes, mas que, na verdade, nada mais eram que fruto das chamadas "ordenanzas del Virrey". Em outros capítulos, Arnaud esclarece detalhes concernentes, inclusive, à nomeação de intérpretes, ao número de profissionais que deveriam atuar simultaneamente em um mesmo pleito, aos honorários cabíveis a tais profissionais, bem como às línguas em que se disponibilizariam, quando legalmente necessários, os serviços de interpretação. Não há, porém, sequer uma única menção a algum tipo de tomada de notas como técnica de apoio na tarefa de interpretação. Há de se supor que o tipo de interpretação utilizado era o de enlace, o que não demandaria necessariamente o uso de uma tomada de notas como aquela que seria desenvolvida posteriormente.

Algumas décadas mais tarde, surgem, já em pleno século $X X$, especialmente na Europa, diversos cursos especializados na formação de intérpretes e tradutores. Dentre as instituições à frente desse processo evolutivo, são dignas de menção especial as seguintes: o Instituto de Formação de Tradutores e Intérpretes de Mannheim (1928), depois incorporado à Universidade de Heidelberg (1933), a Escola de Formação de Tradutores e Intérpretes de Genebra criada na Universidade de Genebra (1941), a Escola de Tradutores e Intérpretes de Viena (1943), os Institutos de Tradução e Interpretação de Innsbruck e Graz (1946), a Escola de Formação Superior de 
RomÃo, T. L. C - A tomada de notas em interpretação consecutiva: algumas considerações históricas

Tradutores e Intérpretes de Germersheim (1947), mais tarde integrada à Universidade de Mainz, a Escola Superior de Intérpretes e Tradutores ESIT/ Paris e o Instituto Superior de Intérpretes e Tradutores - ISIT/ Paris (1957).

Até meados do século passado, a interpretação consecutiva, por um lado, já se firmara como uma realidade incontestável em um mundo com desenvolvimento industrial e comercial a pleno vapor; por outro, também a interpretação simultânea, que já fora experimentada nas primeiras décadas do século XX4 pela empresa IBM, acabaria conquistando especial reconhecimento, sobretudo graças a seu amplo emprego durante os Processos de Nuremberg, em finais dos anos 1940, decorrentes das atrocidades cometidas durante a Segunda Guerra Mundial. Acompanhando esses desenvolvimentos, os institutos de formação de tradutores e intérpretes passaram a estudar sistematicamente, do ponto de vista teórico e prático, essas duas atividades profissionais, dedicandose também à formação de profissionais capacitados para um mercado em constante processo de ampliação. Dentre os estudos a que al guns pesquisadores se dedicaram já a partir da década de 1950, merece realce a elaboração e a prática de técnicas de tomada de notas para interpretação consecutiva. Das várias contribuições surgidas a partir daquela década, serão enfatizados neste capítulo os trabalhos de dois precursores de uma técnica de anotações, nomeadamente, J ean Herbert e François Rozan, bem como as colaborações decisivas prestadas por Danica Seleskovitch e Marianne Lederer, da escola francesa de interpretação, e por Heinz Matyssek, da escola alemã, que elaborou não apenas um manual de técnicas de anotações em interpretação consecutiva, mas também um glossário de símbolos.

\footnotetext{
${ }^{4}$ Sobre a invenção da cabine e demais acessórios de interpretação simultânea, cf. KURZ (1999: 20).
} 
RomÃo, T. L. C - A tomada de notas em interpretação consecutiva: algumas considerações históricas

\section{A evolução da tomada de notas na interpretação consecutiva}

Ao definirem as atribuições cabíveis a um intérprete de negociações (de acompanhamento) ou de enlace (Verhandlungsdolmetscher), os autores do manual Erfolgreich sel bständig als Dolmetscher und Übersetzer - ein Leitfaden für Existenzgründer [Sucesso como intérprete e tradutor autônomo - um manual para novos empreendedores], publicado pela Bundesverband der Dolmetscher und Übersetzer - BDÜ [Associação Alemã de Intérpretes e Tradutores], fazem referência ao papel do Konsekutivdolmetscher [intérprete consecutivo], destacando suas competências desta maneira:

Als Verhandlungsdolmetscher finden Sie z.B. bei Geschäftsverhandlungen, Gesprächen mit Wirtschaftsdelegationen, Betriebsbesichtigungen, Aufsichtsratssitzungen, Fachgesprächen, politischen und kulturellen Begegnungen und auf Messen Einsatz. Die zum Einsatz kommende Dolmetschtechnik ist vor allem das Konsekutivdolmetschen. Eine wichtige Voraussetzung ist daher neben einem guten Gedächtnis die Beherrschung der Notizentechnik. ${ }^{5}$ (BDÜ 1999: 74)

A última frase do trecho supracitado, em especial o relevo dado ao aspecto "neben einem guten Gedächtnis die Beherrschung der Notizentechnik" [o domínio da técnica de anotações para além de uma boa memória], é bastante eloquente, especialmente por partir de uma renomada associação profissional no campo da interpretação e da tradução. Ao fazer tal menção, a BDÜ reforça o que geralmente se ensina em alguns institutos de formação de intérpretes na

\footnotetext{
${ }^{5}$ Como intérprete de negociações, você poderá atuar p.ex. em negociações comerciais, com delegações empresariais, em visitas técnicas a empresas, reuniões de fábricas, reuniões de conselhos administrativos, palestras técnicas, encontros de cunho político e cultural, assim como em feiras internacionais. Nestes casos, a técnica de interpretação utilizada é principalmente a interpretação consecutiva. Por esta razão, um importante pré-requisito é, além de uma boa memória, o domínio da técnica de anotações. (tradução do autor deste artigo)
} 
RomÃo, T. L. C - A tomada de notas em interpretação consecutiva: algumas considerações históricas

Europa: a necessidade de se aprender uma técnica visando a uma tomada de notas que auxilie o intérprete na consecução exitosa de seus serviços.

Em um artigo sobre os diferentes tipos de interpretação, Birgit Strolz, intérprete, professora de interpretação e doutora em Tradução e Interpretação pela Universidade de Viena, resume a tarefa do intérprete consecutivo deste modo:

Konsekutivdolmetschen. Der Dolmetscher sitzt mit den Teilnehmern am Konferenztisch im Sitzungssaal. Während er dem Redner zuhört, macht er sich jene Notizen über das Gehörte, die er als Gedächtnitsstütze braucht, um die in der Ausgangssprache gemachten Aussagen des Redners unmittelbar nach Beendigung der Rede oder eines Redeteils (konsekutiv) vollständig und mit allen Nuancen in die Zielsprache zu übertragen und wie eine eigene Rede vorzutragen. ${ }^{6}$ (STROLZ 1997: 102s.)

0 interesse pela criação de uma técnica de anotações para a interpretação consecutiva surgiu em 1952, com a publicação do livro Manuel de I'interprète, da autoria de Jean Herbert, um intérprete suíço que atuou profissionalmente em diferentes organizações internacionais, tais como a Liga das Nações e a ONU, no período compreendido entre a Primeira e a Segunda Guerra Mundial. Herbert é referência para diversos autores que se dedicaram a escrever sobre interpretação, alguns deles também intérpretes profissionais, como Kellett-Bidoli (2000), Kurz (1996), Matyssek (1989), Rozan (1984), Russo (2000), dentre outros. J ean Herbert, como afirma Kellett-Bidoli, era dotado de especial habilidade para línguas e fez seu début como intérprete em Londres, no ano de 1917:

\footnotetext{
${ }^{6}$ Interpretação consecutiva. 0 intérprete fica sentado à mesa de conferência junto com os palestrantes na sala da reunião. Enquanto ouve atentamente o palestrante, faz suas anotações sobre o discurso, das quais necessitará como apoio para a memória, a fim de traduzir para a língua de chegada (de forma consecutiva) integralmente e com todas as nuances, como se fosse um discurso seu, os enunciados feitos pelo palestrante na língua de partida, tão logo este tenha terminado seu discurso ou parte do discurso. (tradução do autor deste artigo)
} 
RomÃo, T. L. C - A tomada de notas em interpretação consecutiva: algumas considerações históricas

Il suo debutto nell'interpretazione avvenne a Londra. In un negoziato finanziario anglo-francese nel 1917, quando fu chiamato d'urgenza per negoziare un prestito nella casa di Lloyd George con il ministro delle Finanze francese e il governatore della Banque de France durante un'abbondante prima colazione a base di uova e pancetta. Lanciatosi nella carriera d'interprete, partecipò a molte conferenze internazionali, in particolare a quelle della Società delle Nazioni, e fu interprete di alcuni eminenti personalità del XX seccolo quali Barthou, Bénès, Churchill, Clémenceau, de Briand, Lloyd George, Mussolini, Poincaré, Streseman, Strettinus, Wilson. Dopo laa seconda guerra mondiale passò tre anni a organizzare il servizio d'interpretazione della neocostituita ONU e lavorò per ol tre cento organizzazioni internazionali in vaarie parti del mondo. ${ }^{7}$ (KELLETTBIDOLI 2000: 12)

Observando-se esses dados da carreira de Herbert, é possível entender por que motivos ele provavelmente se viu instado ou motivado a conceber uma técnica de anotações para a interpretação consecutiva. Por estar sempre dedicado de forma extrema à profissão que abraçou, certamente entendeu a necessidade de elaborar estratégias práticas, visando a enfrentar a carga diária de trabalho e a evitar um serviço de interpretação consecutiva do tipo frase por frase.

J ean-François Rozan, autor do livro La prise de notes en interprétation consécutive [A tomada de notas em interpretação consecutiva], publicado em 1956, introduz sua obra com esta afirmação: «J ean Herbert, dans son Manuel

\footnotetext{
7 O seu début na interpretação aconteceu em Londres, durante uma negociação financeira anglo-francesa em 1917, quando atendeu a um chamado de urgência para negociar um empréstimo na casa de Lloyd George com o ministro das Finanças francês e o presidente do Banque de France, durante um copioso café da manhã regado a ovos e bacon. Lançado na carreira de intérprete, participou de muitas conferências internacionais, particularmente no âmbito da Liga das Nações, e foi intérprete pessoal de algumas personalidades ilustres do século XX, tais como: Barthou, Bénès, Churchill, Clémenceau, de Briand, Lloyd George, Mussolini, Poincaré, Stresemann, Strettinus, Wilson. Após a Segunda Guerra Mundial, passou três anos organizando o serviço de interpretação da recém-constituída ONU e trabalhou, além disso, para centenas de organizações internacionais em várias partes do mundo. (tradução do autor deste artigo)
} 
RomÃo, T. L. C - A tomada de notas em interpretação consecutiva: algumas considerações históricas

de I'Interprète, a dit tout ce qu'il y avait à dire sur le rôle, la mission, les qualités de l'interprète. $\|$ a tracé les grandes lignes techniques du métier. ${ }^{8}$ 》

Em seu livro, HERBERT (1952: 32) reconhece que a memória por si só não ajudará 0 intérprete a superar todos os impasses de um serviço de interpretação, admitindo que as anotações são 0 fator essencial da interpretação consecutiva. Dessa forma, realiza um trabalho pioneiro, ao propor algumas estratégias de tomada notas que facilitassem o trabalho do intérprete consecutivo empenhado em fazer uso de um bloco de anotações de maneira refletida. Alguns dos seus princípios viriam a ser seguidos e/ ou aperfeiçoados por J ean-François Rozan e, posteriormente, por Heinz Matyssek (1989), intérprete durante o Pós-Guerra e, mais tarde, professor da disciplina de Técnica de Anotações no Instituto de Formação de Tradutores e Intérpretes da Universidade de Heidelberg.

Os princípios básicos propostos por Herbert são: a) anotações bastante visualizáveis; b) uso de símbolos, sempre que possível, em vez de palavras; c) emprego de abreviações; d) uso de linhas e de flechas remissivas, isto é, para remeter a um termo anteriormente anotado na folha do bloco; e) uso de marcadores de ênfase; f) emprego da negação; e g) uso de concatenações lógico-conceituais.

Apoiando-se no trabalho de seu antecessor, Rozan elabora seu manual de tomada de notas com base em sete princípios, a saber: a) transposição da ideia preferencialmente à palavra; b) regras de abreviação; c) concatenações; d) negação; e) acentuação; f) verticalismo; e g) o décalage. Com sua técnica, Rozan reforçava, como já propusera Herbert, que o intérprete se ativesse mais às ideias e menos às palavras isoladas. 0 uso de abreviações obedece a regras, tais como: “En règle générale, l'interprète devra noter le mot abrégé, sauf

\footnotetext{
${ }^{8} \mathrm{~J}$ ean Herbert, em seu Manuel de I'Interprète [Manual do Intérprete], disse tudo o que havia a dizer sobre o papel, a missão, as qualidades do intérprete. Ele traçou as grandes linhas técnicas da profissão. (tradução do autor deste artigo)
} 
RomÃo, T. L. C - A tomada de notas em interpretação consecutiva: algumas considerações históricas

quand il s'agit d'un mot court (quatre ou cinq lettres au plus). 9" Pode-se imaginar, todavia, o grande número de abreviações a que o intérprete devia recorrer durante a tomada de notas. Ao retornar às anotações, certamente se via, de alguma forma, preso à palavra abreviada, o que negaria seu primeiro princípio. Com o uso de notas verticais, em que as componentes frasais do texto não mais precisavam seguir a ordem horizontal da mesma frase em sua forma escrita, Rozan ressaltava a necessidade de se apresentarem as notas de forma facilmente visualizável. A técnica de décalage ajudava a retomar um mesmo tema em uma mesma sequência, sem a necessidade de repeti-lo por escrito, mas apenas com a indicação de um símbolo (p.ex. uma linha). Veja-se, a seguir, um exemplo de anotação extraído do próprio manual de J ean-François Rozan:

3. En especial creemos del mayor interés el análisis que se hace de los problemas que plantea el comercio internacional.

4. Así en la eIntroducción : al Informe Económico Mundial como en el estudio monográfico "La liberalización del Comercio Internacional s, se contiene un claro análisis teórico y práctico de la situación, el cual, indudablemente, ha de facilitarnos la adopción de las medidas más adecuadas para hacer frente a esos problemas.

5. Quisiéramos hacer resaltar una aserción contenida en el Informe Económico Mundial: alli se dice que aun cuando el comercio internacional y su fomento interesan naturalmente a todos los países, para algunos constituye una necesidad vital.

6. Tal afirmación es verdadera, tanto para Venezuela como para la mayoría de los países de la región geográfica a la cual pertenece. De ahí el profundo interés con el cual se enfrentan nuestros países a los problemas que atañen al comercio internacional.

7. Es, en efecto, principalmente mediante la intensificación de su comercio exterior, y mediante el mantenimiento de una equitativa relación de intercambio para los pro-

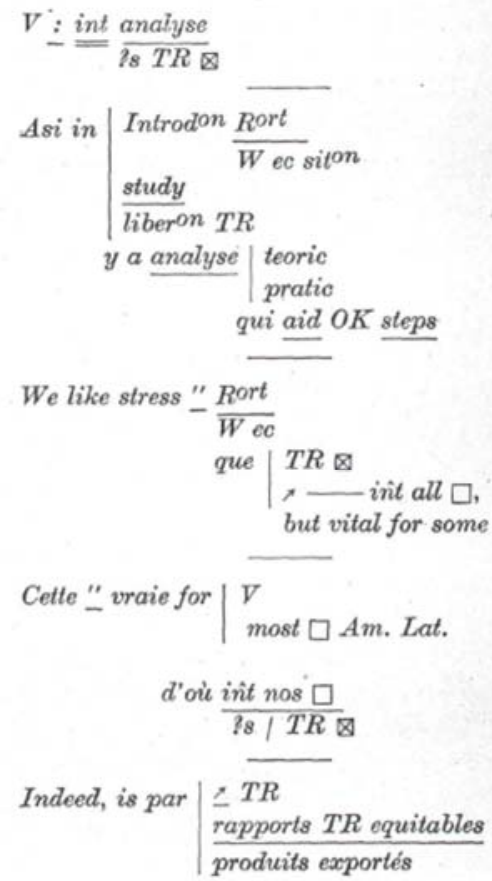

Fig. 1 Extraído de RozAN, J.-F. La prise de notes en interprétation consécutive. Genebra: Librairie de I'Université Georg \& Cie. S.A., 1984. pp.10.

\footnotetext{
${ }^{9}$ Como regra geral, o intérprete deverá anotar a palavra de forma abreviada, exceto quando se tratar de uma palavra curta (no máximo quatro ou cinco letras). (tradução do autor deste artigo)
} 
RomÃo, T. L. C - A tomada de notas em interpretação consecutiva: algumas considerações históricas

Na segunda edição de sua obra Pédagogie raisonnée de l'interprétation (2002), Danica Seleskovitch, em parceria com Marianne Lederer, revigora as bases da tomada de notas em interpretação consecutiva, que a primeira já lançara nos anos 1970 (SELESKOVITCH 1975). Dentre os elementos de uma técnica de anotações, as autoras (SELESKOVITCH \& LeDERER 2002: 49ss.) ressaltam estes aspectos: a) as notas não devem ser uma tradução literal das palavras pronunciadas em discursos com uma duração entre 15 e 30 minutos; b) as notas devem servir como apoio para a memória do intérprete no momento de restituir as palavras pronunciadas pelo palestrante; c) devem-se anotar as ideias essenciais de um discurso mediante palavras, símbolos, desenhos etc.; d) também se devem anotar as relações de causalidade, consequência etc., assim como as relações temporais; e) antropônimos, topônimos, numerais, termos técnicos e enumerações devem ser igualmente alvo de uma tomada de notas.

No final dos anos 1980, Heinz Matyssek publicou o seu Handbuch der Notizentechnik für Dolmetscher: ein Weg zur sprachunabhängigen Notation [Manual de técnica de anotações para intérpretes: um caminho para uma tomada de notas independente de língua]. Nas três décadas que antecederam essa publicação, Matyssek trabalhara como intérprete e, posteriormente, também como professor da disciplina Notizentechnik für Konsekutivdolmetscher [Técnica de Anotações para Intérpretes Simultâneos] no Instituto de Formação de Tradutores e Intérpretes da Universidade de Heidelberg. No prefácio de seu livro, Matyssek já deixa claro que sua iniciativa surgiu ao ver que "(...) Konsekutivdolmetschen ohne ein solches grundlegend undd systematisch erarbeitetes Hilfsmaterial in der Regel erfolgreich nicht zu bewerkstelligen sei10" (MATYSSEK 1989: V). Na elaboração de seu manual, Matyssek recorreu a seus predecessores, Herbert e Rozan, bem como foi leitor dos trabalhos publicados por Seleskovitch e Lederer. Ademais, empenhou-se em superá-los com sua firme intenção de elaborar uma técnica de anotações que

10 “(...) em geral, a interpretação consecutiva não poderia ser realizada com êxito sem um material de apoio desse tipo elaborado de forma minuciosa e sistemática." (radução do autor deste artigo) 
RomÃo, T. L. C - A tomada de notas em interpretação consecutiva: algumas considerações históricas

fosse uma "sprachlose Notation", isto é, uma tomada de notas "sem língua", supralinguística, que não dependesse das línguas envolvidas no processo de interpretação.

Para alcançar o seu intuito, ou pelo menos aproximar-se o máximo possível de sua meta, Matyssek defende, em seu manual, a ideia de que se deve "esquecer a palavra". Segundo ele, é preciso que o intérprete consecutivo siga os seguintes passos durante a execução de sua tarefa (MATYSSEK 1989: 35s):

a) ouvir atentamente e realizar o processo de compreensão;

b) fazer uma análise do sentido dos enunciados do palestrante;

c) reter na memória entre 60 e $80 \%$ da fala do palestrante;

d) tomar nota entre 20 e $40 \%$ da fala do palestrante;

e) realizar o output, a reprodução (re)ordenada, na língua de chegada, da fala do palestrante, fazendo jus às intenções deste e sendo fiel ao sentido de sua fala, sem buscar uma vinculação a cada palavra.

Apenso a seu manual, Matyssek também publicou um dicionário com vários símbolos criados para diferentes áreas do conhecimento e da atuação humana, tais como: política, economia, agricultura, indústria etc. Durante seus cursos na Universidade de Heidelberg, dos quais o autor deste texto também participou no início dos anos 1990, sempre ressaltava que os melhores símbolos eram aqueles que o próprio intérprete criava e punha em prática. Para ilustrar como essa técnica de anotações já fez e continua a fazer escola, vejam-se abaixo alguns exemplos de símbolos propostos em um manual editado na Espanha, mas com clara influência de Matyssek: 
RomÃo, T. L. C - A tomada de notas em interpretação consecutiva: algumas considerações históricas

\begin{tabular}{|c|c|c|c|}
\hline$\sqcap$ & Vustar & $m$ & Medidat \\
\hline ○ & Debates & $\ell$ & Pay \\
\hline Q & Sector, namo & 0 & conbribucion \\
\hline (3) & Imagen reflegor & $\mathbb{R}$ & Resultado \\
\hline$U$ & $\begin{array}{l}\text { Puntor de } \\
\text { inplexion }\end{array}$ & (9) & Integracion \\
\hline\langle\rangle & Dralogo & T & Proteccion \\
\hline ○ & Vuiciongeneral & (2) & Preocupacion \\
\hline ( & Ventaya & $\Theta$ & Dessentaija \\
\hline$P^{\circ}$ & anfition & ฑ & Mospitaildad \\
\hline
\end{tabular}

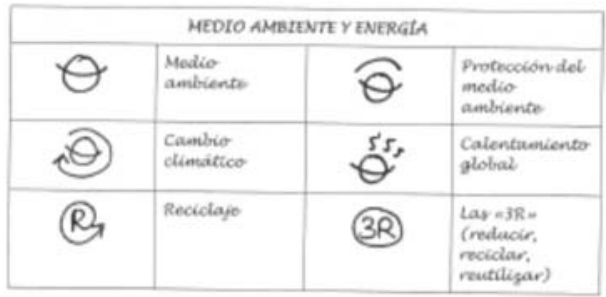

Fig. 2 Extraído de MARCH, C. B. Técnicas de interpretación consecutiva: la toma de notas. Manual para el estudiante. Granada: Editorial Comares, 2012. pp. 42

Em busca de seus objetivos, Matyssek tomou decisões bastante inovadoras, em comparação aos autores dos trabalhos que o antecederam. Um de seus lemas era a não-dependência da palavra isolada [Wortfreiheit]. Conforme Matyssek, para conseguir libertar-se de cada palavra do texto ouvido, o intérprete precisa, portanto, recorrer a uma técnica de anotações que privilegie "símbolos não palavras" [Nichtwort-Symbole], isto é, símbolos que substituam palavras. Também insiste em que se recorra o mínimo possível a abreviações. Uma vez encontrado um símbolo que realmente traduza uma palavra e seus sinônimos, tal símbolo deverá ganhar o mesmo valor correspondente em outras línguas. 0 símbolo < por exemplo, que deve ser entendido como uma boca aberta a falar, significa dizer, mas também falar, exprimir, expressar, manifestar, explicar, pronunciar, comunicar etc. Da mesma maneira, os significados destas palavras em outras línguas deveriam ser associados ao mesmo símbolo < (p.ex.: to say, to speak; dire, parler; decir, hablar; sagen, sprechen; dire, parlare etc.). No exato momento da audição do 
RomÃo, T. L. C - A tomada de notas em interpretação consecutiva: algumas considerações históricas

texto, a memória do intérprete, aliada ao rápido, mas sempre muito atento processo de análise, compreensão e assimilação do sentido do discurso proferido pelo palestrante, deverá entrar em ação, a fim de que, no exato momento da reprodução do sentido do discurso para a língua-cultura de chegada, o intérprete saiba se, por exemplo, se trata deste ou daquele verbo.

A folha de anotações proposta por Matyssek ganha uma pequena margem esquerda, onde são anotados os suj eitos da frase, os vocativos e as conj unções. A "frase" anotada obedece ao critério vertical já proposto por Rozan, mas os símbolos devem ser dispostos de maneira bastante visualizável no bloco, sem se poupar muito espaço. Uma vez estabelecido o sujeito da frase, que poderá ser anotado, isto é, simbolizado, ou simplesmente retido na memória, a frase segue, na horizontal, para a construção de seu predicado (verbos, complementos e demais termos acessórios); em seguida, a anotação segue uma linha descendente, em obediência ao verticalismo, seja porque terá aparecido uma conjunção coordenativa ou subordinativa, seja porque, por questão de clareza, o predicado será estendido na vertical, permitindo uma rápida visualizável no momento da reprodução oral. No caso de enumerações, estas sempre deverão ser dispostas, da maneira mais inequívoca possível, na vertical, como já propugnavam Herbert, Rozan, e Seleskovitch/ Lederer.

\section{Considerações finais}

Este artigo refere-se, de início, à prática da interpretação de enlace e encontra seu ponto fulcral, em uma segunda parte, na análise voltada para a tomada de notas em interpretação consecutiva, modalidade em que se reproduzem oralmente, de uma língua-cultura $A$ para uma língua-cultura $B$, discursos ou trechos de discursos com sentido completo. Desta maneira, entende-se como válida, em comunhão com os autores mencionados neste 
RomÃo, T. L. C - A tomada de notas em interpretação consecutiva: algumas considerações históricas

trabalho, a necessidade de uma técnica de anotações que auxilie o intérprete consecutivo.

J ean Herbert e J ean-François Rozan, dois grandes precursores da tomada de notas em interpretação consecutiva, sempre deverão ser lembrados por seus trabalhos pioneiros, visando a uma facilitação do trabalho do intérprete consecutivo, que antes ficava à mercê da própria memória ou tinha de recorrer a uma frequente quebra do discurso através do método de interpretação frasepor-frase.

Igualmente se devem mencionar os trabalhos iniciados, na escola francesa de interpretação de conferências, por Danica Seleskovitch e aprofundados posteriormente por ela e sua colega Marianne Lederer, que, a partir dos trabalhos de Herbert e Rozan, contribuíram indubitavelmente para a evolução da tomada de notas em interpretação consecutiva.

0 aporte teórico-prático trazido por Heinz Matyssek, que, por sua vez, pôde recorrer aos legados de Herbert, Rozan, Seleskovitch e Lederer, dentre outros autores, merece especial destaque por sua proposta inovadora, em que o intérprete passa a recorrer a símbolos, tentando captar, antes de tudo, 0 sentido do discurso, esquecendo, o máximo possível, o sentido de cada palavra isoladamente. Mediante anos de prática profissional como intérprete e também como formador de intérpretes consecutivos, Matyssek conseguiu casar, de maneira eficaz, teoria e prática no âmbito da interpretação consecutiva. Com seus livros e suas orientações no Instituto de Formação de Tradutores e Intérpretes da Universidade de Heidelberg, Matyssek pôs a lume, com veemência, a necessidade de se entender que um intérprete consecutivo também atua como palestrante, precisando, pois, além da memória, de um suporte técnico, mediante uma técnica eficaz de tomada de notas, que o auxilie principalmente em trechos de maior fôlego. 
RomÃo, T. L. C - A tomada de notas em interpretação consecutiva: algumas considerações históricas

\section{Referências bibliográficas}

ARnAUD, V.G. Historia y legislación de la profesión de traductor público. Buenos Aires: Establecimientos Gráficos E. G. L. H., 1958.

Bueno, E. A viagem do descobrimento. A verdadeira história da expedição de Cabral. Rio de J aneiro: Objetiva, 1998.

BUNDESVERBAND DER DOLMETSCHER UND ÜBERSETZER E.V. Erfolgreich selbständig als Dolmetscher und Übersetzer. Ein Leitfaden für Existenzgründer. Tübingen: Stauffenburg Verlag Brigitte Narr GmbH, 1999.

Falbo, C.; Russo M. \& Straniero Sergio, F. Interpretazione simultanea e consecutiva. Problemi teorici e metodologie didattiche. Milão: Ulrico Hoepli Editore S.p.A., 1999.

HERBERT, J . Manuel de l'interprète. Genebra: Georg \& Co., 1952.

HERÔDOTOS. HISTÓRIA. Trad. Mário da Gama Kury. Brasília: Editora da Universidade de Brasília, 1988.

HuRTADO-AlBiR, A. Traducción y Traductología. Madrid: Ediciones Cátedra, 2001.

Kellett Bidoli, C.J . Aspetti storici dell'interpretazione. In: Falbo, Caterina; et al. Interpretazione simultanea e consecutiva. Problemi storici e metodologie didattiche. Milão: Ulrico Hoepli Editore S. pa. A., 1999.

KURZ, I. Simultandolmetschen als Gegenstand der interdisziplinären Forschung. Wien: WUV-Universitätsverlag, 1996.

MARCH, C. B. Técnicas de interpretación consecutiva: la toma de notas. Manual para el estudiante. Granada: Editorial Comares, 2012. pp. 42.

MatYSSEK, H. Handbuch der Notizentechnik für Dolmetscher: ein Weg zur sprachunabhängigen Notation. Vol. I e II. Heidelberg: Groos, 1989.

RoZAN, J. - F. La prise de notes en interpretation consécutive. Genebra: Librairie de I'Université Georg \& Cie. S. A., 1984.

SELESKOVITCH, D. Langage, langues et mémoire: études de la prise de notes en interprétation consécutive. Paris: Minard Lettres Modernes, 1975.

SELESKOVITCH, D.; Lederer, M. Pédagogie raisonée de I'interprétation. Clamecy ; Didier Érudition, 2002. 
RomÃo, T. L. C - A tomada de notas em interpretação consecutiva: algumas considerações históricas

STROLZ, B. Konferenzdolmetschen: Fertigkeit oder Kunst? In: KURZ, Ingrid; MoISL, Angela (Eds.). Berufsbilder für Übersetzer und Dolmetscher. Perspektiven nach dem Studium. Viena: WUV-Universitätsverlag, 1997. 